\title{
SOUND BODY, SOUND MIND-THE IMPACT OF THE MENTAL HEALTH PARITY ACT OF 2008
}

\author{
Leigh Stuckhardt*
}

\section{INTRODUCTION}

On October 3, 2008, in response to bank and lending house failures and the worst economic downturn since the Great Depression, President Bush signed into law the Emergency Economic Stabilization Act of 2008, more commonly known as the "bailout bill." As funds from the financial relief program created by the bailout bill, the Troubled Assets Relief Program (TARP), are spent to slowly reverse the economic recession, another positive effect of the bailout bill has already taken hold in an area having nothing to do with financial markets - health insurance coverage for Americans suffering from mental illness. This is because, buried within the Emergency Economic Stabilization Act, is the Paul Wellstone and Pete Domenici Mental Health Parity and Addiction Act of 2008 (the "2008 Act")—-legislation that requires parity in insurance coverage for physical and mental illness. ${ }^{2}$

This paper will examine the stigma associated with mental illness, and the ways in which that stigma has led to a chain of legislative advances to improve access to mental health care. Part II of this paper will define the mental illness stigma as the unfounded belief that mental health is distinct from physical health, and will survey the ways this belief has played out in the courts. Part III will outline the path toward parity legislation, and will analyze the shortcomings of the first parity legislation - the Mental Health Parity Act of 1996 - and the improvements offered in the Mental Health Parity Act of 2008. Part IV will examine the limitations of the 2008 Act, and Part V will examine the efficacy with which healthcare reform legislation addressed these

\footnotetext{
* $\quad$ Leigh A. Stuckhardt, B.S. Carnegie Mellon University, 2007, J.D. with Certificate in Health Law, University of Pittsburgh School of Law, 2010.

1. Robert Pear, Bailout Provides More Mental Health Coverage, N.Y. Times, Oct. 6, 2008, at A13.

2. Posting of Jacob Goldstein to The Wall Street Journal Health Blog, http://blogs.wsj.com/health/ 2008/10/02/senate-folds-mental-health-parity-into-wall-street-bailout-bill/ (Oct. 2, 2008, 12:14 EST).
} 
limitations. Finally, Part VI of this paper will suggest further steps that must be taken to improve mental healthcare in the U.S. beyond healthcare reform and the 2008 Act.

\section{The Stigma Associated with Mental Illness}

The push for equal insurance coverage for physical and mental illness stems from the broader goal of eliminating the stigma associated with mental illness. This stigma is manifested by fear and bias, results in the public's unwillingness to employ, rent to, and socialize with the mentally ill, and deters mentally ill individuals from seeking health care. ${ }^{3}$ Proponents of mental health parity legislation believe health insurance companies use this stigma to their advantage in denying coverage. In his remarks to the House of Representatives regarding what would eventually become the 2008 Act, U.S. Representative George Miller ${ }^{4}$ noted that only one-third of the forty-four million Americans who suffer from mental illness actually receive treatment. He attributed this disparity to health insurers providing less coverage for mental illness and substance abuse than for other conditions. ${ }^{5}$

The lack of parity in insurance benefits stems, at least in part, from the belief that mental illness is distinct from and subordinate to physical illness. ${ }^{6}$ This belief persists even despite the abundance of scientific research on mental illness, and the efficacy of the treatments that exist for an array of mental disorders. ${ }^{7}$ Proponents of parity legislation stress that mental illnesses, like physical illnesses, are biological disorders and should therefore be treated similarly. ${ }^{8}$ The National Alliance on Mental Illness (NAMI), the leading mental health advocacy organization in the United States, notes on its "About Mental Illness" fact sheet that mental illnesses are "biologically based brain disorders." NAMI argues that "stigma erodes confidence that mental

3. Office of the Surgeon General, Mental Health: A Report of the Surgeon General at 6, available at http://www.surgeongeneral.gov/library/mentalhealth/pdfs/c1.pdf (last visited Apr. 6, 2010).

4. D-CA, Chairman of the House of Representatives Education and Labor Committee, 110th Congress.

5. Press Release, U.S. Representative George Miller, Chairman, U.S. House of Representatives Comm. on Educ. \& Labor, Chairman Miller Floor Statement on H.R. 6983, the "Paul Wellstone-Pete Domenici Mental Health and Addiction Equity Act" (Sept. 23, 2008), available at http: www.house.gov/ apps/list/speech/edlabor_dem/092308FStatementMentalParity.html.

6. See supra note 3 , at 3 .

7. Id.

8. See Fred Fromer, After 12 Years, Wellstone Mental Health Parity Act is Law, A.P., Oct. 3, 2008, available at $\mathrm{http}: / /$ minnesota.publicradio.org/display/web/2008/10/03/parity_finalpassage/?refid=0.

9. National Alliance on Mental Illness, What Is Mental Illness: Mental Illness Facts, http:// 
disorders are real, treatable health conditions," and that the stigma against mental illness has led to "attitudinal, structural, and financial barriers to effective treatment and recovery." 10

The issue of whether mental illness is biological in nature has also been addressed in the courts, where several suits have been filed by health plan members seeking reimbursement for mental health treatment. These cases turned on the nature of mental illness and its treatment, and on the extent to which insurance for physical illness would cover physical manifestations of mental illness. In Arkansas Blue Cross \& Blue Shield v. Doe,${ }^{11}$ the Arkansas Court of Appeals agreed with the plaintiff that, despite the presence of behavioral symptoms, bipolar disorder is a physical illness, thereby entitling the subscriber to reimbursement under the policy's benefits for physical illnesses, which were more generous than the benefits offered for mental illness. ${ }^{12}$ In Kunin v. Benefit Trust Life Insurance Co.,${ }^{13}$ the plaintiff, seeking reimbursement for medical bills related to his child's treatment for autism, claimed that the insurance company improperly characterized autism as a disease subject to the policy's annual limit on benefits for "mental illness or nervous disorders." ${ }^{14}$ Kunin further argued that term "mental illness" was ambiguous because the policy did not define or explain the term, and did not offer any illustration of conditions the term included or excluded..$^{15}$ The Ninth Circuit Court of Appeals agreed and construed the ambiguity against the insurance company. ${ }^{16}$ In Simons v. Blue Cross \& Blue Shield of Greater New York, ${ }^{17}$ the New York Court of Appeals agreed with the plaintiff that treatment of anorexia nervosa is intended to address the disorder's physical manifestations (including weight loss and malnutrition), and that the insurance company should therefore reimburse the plaintiff according to its benefits for physical illness. ${ }^{18}$ In contrast, the California Court of Appeals, in Equitable Life Assurance Society v. Berry, ${ }^{19}$ rejected plaintiff's contention that manic

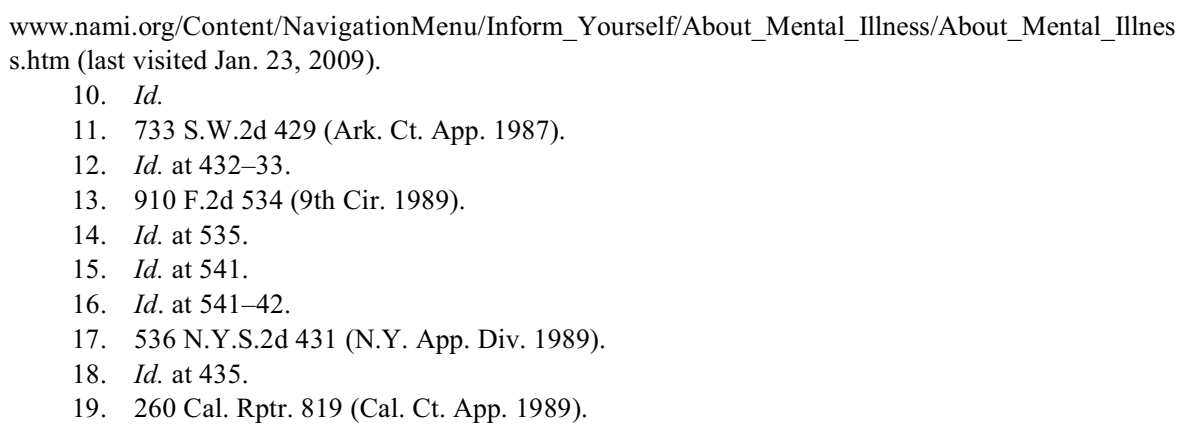


depression, as a genetic illness with physical manifestations, fell under the insurance policy's coverage guidelines for physical illnesses. ${ }^{20}$

These cases suggest that society's confusion regarding the appropriate definition of "mental illness" extends to the courts. Such confusion only strengthens the argument for parity between mental and medical health benefits, and necessitates legislation such as the Mental Health Parity Act of 2008 to protect the interests of the mentally ill.

\section{The Path Toward Parity}

\section{A. The Mental Health Parity Act of 1996, and Where It Went Wrong}

The 2008 Act is the result of twelve years of lobbying by David Wellstone, son of the late Minnesota Senator Paul Wellstone (D-MN), who was a strong advocate for mental health parity in insurance coverage. ${ }^{21}$ In 1996, Senator Wellstone, along with Senator Pete Domenici, ${ }^{22}$ took the first step in eliminating discrepancies in insurance coverage for physical and mental illness when they introduced legislation banning insurance plans from setting lower spending limits for mental illness as compared to those set for physical illness. This legislation became the Mental Health Parity Act of 1996 ("the 1996 Act"). ${ }^{23}$

However, it soon became clear that the 1996 Act fell short of achieving the parity goals so desperately sought by mental health advocates. One such shortcoming was that was that the 1996 Act did not apply to benefits for chemical dependency or substance abuse. ${ }^{24}$ Section (e)(4) of the act stated that within the act, the term "mental health benefits" was defined as "benefits with respect to mental health services ... but does not include benefits with respect to treatment of substance abuse or chemical dependency." 25

Another shortcoming of the 1996 Act was that the act was limited to providing for parity in aggregate lifetime and annual limits for healthcare benefits. ${ }^{26}$ The statute stated that if a health insurance or group health plan did not limit lifetime medical and surgical benefits a subscriber could receive,

20. Id. at $824-25$.

21. Frommer, supra note 8 .

22. $I d$.

23. See id.

24. U.S. Department of Labor, Employee Benefits Security Administration, Fact Sheet: The Mental Health Parity Act, http://www.dol.gov/ebsa/newsroom/fsmhparity.html (last visited Jan. 28, 2009).

25. Parity in Mental Health and Substance Use Disorder Benefits, 29 U.S.C.A $\S 1185$ a(e)(4) (2008).

26. 29 U.S.C.A $\S 1185 a(a)$. 
then the plan could not impose such a limit on mental health benefits. ${ }^{27}$ Similarly, if a plan did not limit annual spending on medical and surgical benefits, then the plan could not impose such a limit on mental health benefits. ${ }^{28}$ Further, if a plan included an annual limit on medical and surgical benefits, the plan had to either apply the same annual limit to medical and surgical benefits as it would apply to mental health benefits, or not include a limit for mental health benefits that was less than that for medical and surgical benefits. ${ }^{29}$ These provisions of the 1996 Act, while providing for parity in spending on mental health versus medical and surgical benefits, fell short of full parity. Parity in duration, amount, and scope of benefits were not addressed, leaving health insurance providers substantial leeway to impose limitations on coverage for mental health care. For example, under the 1996 Act, providers could limit the number of visits to a mental health physician that would be covered, thereby limiting access to mental health care despite parity in annual and lifetime benefits. ${ }^{30}$ Andrew Sperling, director of federal legislative advocacy for the National Alliance on Mental Illness, commented that for too long, health plans have tried to control costs by putting constraints on coverage for mental health. ${ }^{31}$ Further, "people often end up going to the hospital once or twice and exhausting coverage, especially in cases of severe mental illness like schizophrenia or bipolar disorder." ${ }^{32}$ It seems clear, then, that the 1996 Act's controls over annual and lifetime spending did little to improve patients' ongoing and day-to-day care.

The 1996 Act was also limited in that it failed to require parity in co-pays and deductibles paid for mental health versus medical and surgical benefits. ${ }^{33}$ Just as limiting the allowed number of visits for mental health benefits reduced access to mental health care for health insurance subscribers, increasing the co-payment to be paid at each visit to a mental health provider makes visits more expensive, arguably discouraging subscribers' use of mental health services. The 1996 Act also allowed group health plans to restrict coverage of mental health services to only in-network providers, despite the

27. 29 U.S.C.A $\S 1185 \mathrm{a}(\mathrm{a})(1)(\mathrm{A})$.

28. 29 U.S.C.A $\S 1185 \mathrm{a}(\mathrm{a})(2)(\mathrm{A})(2008)$.

29. 29 U.S.C.A $\S 1185 \mathrm{a}(\mathrm{a})(2)(\mathrm{B})(\mathrm{i}-\mathrm{ii})(2008)$.

30. U.S. Department of Health and Human Services, The Mental Health Parity Act, available at http://www.cms.hhs.gov/HealthInsReformforConsume/04_TheMentalHealthParityAct.asp (last visited Nov. 8, 2009).

31. Tammy Worth, Mental Health Coverage Gets Shot at Parity, L.A. Times, Oct. 13, 2008, at F3.

32. $I d$.

33. 29 U.S.C.A $\S 1185 a$. 
plans' coverage for out-of-network medical and surgical benefits. ${ }^{34}$ Like increased co-payments and deductibles, restricting subscribers to in-network mental health service providers decreased access to mental health benefits because only the most cost-effective providers were included in the plan's network. Additionally, patients received little or no coverage for treatment from out-of-network specialists, even if those providers were better able to treat their condition.

In May 2000, the United States General Accounting Office (GAO) released a study on the effectiveness of the 1996 Act. $^{35}$ The study polled employers whose health care plan offerings were affected by the 1996 legislation. The study reported that as of December 1999, eighty six percent of employers who responded to the GAO survey reported that they were in compliance with the 1996 Act, compared to fifty five percent of responding employers who offered parity in annual and lifetime limits for mental and physical health benefits before the legislation's enactment. ${ }^{36}$ However, the GAO found that despite the increased parity offerings and compliance with the 1996 Act, the act's limited scope, coupled with the reductions in mental health benefits that were made to offset the act's requirements, resulted in a situation in which compliance failed to increase employee health plan subscribers' access to mental health care. ${ }^{37}$ The GAO also found that eighty seven percent of those employers who were in compliance with the 1996 Act still offered plans where at least one aspect of their health coverage was more restrictive for mental health benefits than for medical and surgical benefits. ${ }^{38}$ For example, a health care plan might offer limited outpatient office visits and increased outpatient copayments for mental health benefits as compared to medical and surgical benefits. ${ }^{39}$ Further, some of these restrictions were adopted in direct response to the annual and lifetime spending limits imposed by the 1996 Act. $^{40}$ That is, as health care plans attempted to achieve parity in annual and lifetime spending between mental health benefits and medical and surgical benefits, they cut certain mental health benefits to equalize costs. From the GAO study, it became clear that the 1996 Act had fallen far short of

34. See id.

35. U.S. Gen. Accounting Office, Mental Health Parity Act: Despite New Federal Standards, Mental Health Benefits Remain Limited 3 (2000).

36. See id. at 5.

37. See id.

38. See id.

39. See id. at 12 .

40. See id. at 5 . 
its intended goal - eliminating systemic discrimination against health plan subscribers in need of mental health care.

\section{B. Parity, Improved -The Mental Health Parity Act of 2008}

In response to the shortcomings of the 1996 Act, the 2008 Act extends the reach of the prior parity legislation in several ways. First, the 2008 Act strips the 1996 Act's explicit exclusion of substance abuse and chemical dependence benefits from parity coverage, and extends parity coverage to "substance abuse disorder benefits" in addition to benefits for mental health care. ${ }^{41}$ While the inclusion of required coverage for substance abuse was controversial, it ultimately gained the support of employers, who have found that providing healthcare coverage for mental illness and substance abuse is ultimately cost effective, because it increases workers' productivity and reduces the number of days employees must be absent from work. ${ }^{42}$ In fact, in discussions about what would be included in the final version of the Mental Health Parity Act, employers objected not to the inclusion of coverage for substance abuse disorders, but to a requirement that insurers cover treatment for any conditions listed in the American Psychiatric Association's Diagnostic and Statistical Manual of Mental Disorders - a list that includes such conditions as jet lag and caffeine intoxication. ${ }^{43}$

The second improvement the 2008 Act makes over its predecessor is that rather than calling for parity in aggregate annual and lifetime benefits, it calls for parity in annual and day-to-day expenses paid by health plan subscribers. ${ }^{44}$ The 2008 Act provides:

In the case of a group health plan ... that provides both medical and surgical benefits and mental health or substance use disorder benefits, such plan or coverage shall ensure that-

(i) the financial requirements applicable to such mental health or substance use disorder benefits are no more restrictive than the predominant financial requirements applied to substantially all medical and surgical benefits covered by the plan . . . and there are no separate cost sharing requirements that are applicable only with respect to mental health or substance use disorder benefits. ${ }^{45}$

41. Mental Health Parity Act of 2008, Pub. L. No. 110-343, § 512(a)(4).

42. Pear, supra note 1.

43. $I d$.

44. 29 U.S.C. $\S 1185$ a (2006). Paul Wellstone and Pete Domenici Mental Health Parity and Addiction Equity Act of 2008, Pub. L. No. 110-343, § 512, 122 Stat. 3881.

45. Id. at $\S 512(\mathrm{a})(1), 122$ Stat. 3881 (to be codified as amended at 29 U.S.C $\S 1185 \mathrm{a}(\mathrm{a})(3)(\mathrm{A})(\mathrm{i})$ (2006)). 
The act goes on to define "financial requirement" as including "deductibles, copayments, coinsurance, and out-of-pocket expenses, but exclud[ing] an aggregate lifetime limit and an annual limit." ${ }^{, 46}$ The 2008 Act's call for parity in more short-term payments by health plan subscribers, such as copayments and deductibles, rather than for aggregate spending represents a significant improvement over the 1996 Act, because it prevents insurers from offering mental health benefits that are more expensive per visit than are medical and surgical benefits.

A third improvement the 2008 Act makes over the 1996 Act is that it requires parity in an insurance plan's treatment limits. ${ }^{47}$ The 2008 Act defines treatment limits as including "limits on the frequency of treatment, number of visits, days of coverage, or other similar limits on the scope or duration of treatment," and states that treatment limits applicable to mental health or substance abuse benefits may be no more restrictive than are the limits on medical and surgical benefits. ${ }^{48}$ This provision of the 2008 Act directly addresses the inequality in access that remained even after the enactment of the 1996 legislation. Since the 1996 Act only called for parity in aggregate annual and lifetime spending on mental health versus medical and surgical health benefits, insurers imposed limits on the scope and duration of covered mental health benefits. Under the new act, health plan subscribers should have improved access to mental health care without running the risk of exhausting their allotted benefits, particularly for ongoing illnesses that require repeated visits to a mental health practitioner.

Finally, the Mental Health Parity Act of 2008 improves on the 1996 Act because it requires parity in out-of-network coverage for mental health and physical health benefits. ${ }^{49}$ The act says:

In the case of a plan or coverage that provides both medical and surgical benefits and mental health or substance use disorder benefits, if the plan or coverage provides coverage for medical or surgical benefits provided by out-of-network providers, the plan or coverage shall provide coverage for mental health or substance use disorder benefits provided by out-of-network providers. ${ }^{50}$

\footnotetext{
46. 29 U.S.C $\S 1185 \mathrm{a}(\mathrm{a})(3)(\mathrm{B})(\mathrm{i})(2009)$.

47. Id.

48. 29 U.S.C $\S 1185 \mathrm{a}(\mathrm{a})(3)(B)(\mathrm{iii})(2009)$.

49. Id.

50. 29 U.S.C § $1185 a(a)(5)(2009)$.
} 
The out-of-network coverage provision means that if an insurer provides any coverage for care received out-of-network (that is, by a medical professional not included in the subscriber's health insurance plan), the insurer must provide equal coverage for mental health care received out-of-network. This provision improves access to mental health benefits because it allows subscribers to seek out treatments not covered by their health care plans. The provision is particularly important in cases where an out-of-network specialist is needed to treat the subscriber's condition.

\section{The Limitations of the 2008 Act}

While the Mental Health Parity Act of 2008 goes a long way to improve access to mental health care, the act also has significant limitations. One such limitation is that the act only applies to large group health insurance plans with fifty or more employees. ${ }^{51}$ It does not require parity in the healthcare plans offered by small business, or in the plans that individuals purchase in the open market. This means that mentally ill people in the small business and individual insurance markets are still disclosed from the protections offered by the 2008 Act - if their healthcare plans offer mental health benefits at all.

Another limitation of the 2008 Act is that it does not require insurers to provide mental health benefits in the first place. Rather, the act only applies to health care plans that already include mental health benefits, and does not prevent insurers from simply dropping mental health benefits altogether if costs increase too much. While some states protect against this possibility by mandating a certain minimum level of mental health benefits, the failure to address the issue in federal law subjects employees to a patchwork of state regulation. ${ }^{52}$ Further, an employee whose employer-provided insurance does not include mental health benefits would face the choice of changing jobs, or purchasing separate mental health coverage.

Similarly, the 2008 Act is limited because the provision of mental health benefits according to the parity requirements of the act depends upon the provision of those same benefits for physical illness. That is, absent state laws mandating a minimum level of mental health benefits that must be included in healthcare plans, an employee will receive benefits that are only as generous as are the plan's benefits for medical care. The problem with this

51. Pub. L. No. $110-343 \S 512(\mathrm{c})(3)(A), 122$ Stat. 3889 (to be codified as amended at I.R.C. $\S 9812(\mathrm{c})(1)(\mathrm{B}))$.

52. Cong. Research Service, Mental Health Parity Act: Federal and State Action and ECONOMIC IMPACT 6 (2008). 
aspect of the 2008 Act is that it could actually have an adverse effect on access to care, because employers could reduce benefits or eliminate mental health benefits entirely. For example, under the 2008 Act, a health insurance provider that wants to keep costs constant may still comply with the act's parity requirements if it simply reduces coverage for medical and surgical services, raises copayments, deductibles, and coinsurance payments across the board, or applies stricter treatment limitations across all covered benefits. And cost may be a significant factor in the implementation of the 2008 Act, which is expected to increase healthcare costs. The Congressional Budget Office has predicted that the legislation could increase group healthcare premiums an average of 0.2 to $0.4 \%{ }^{53}$ However, this may be a conservative estimate. A 1998 study by the Substance Abuse and Mental Health Services Administration, a division of the U.S. Department of Health and Human Services, estimated that full parity could cause health plan premiums to increase anywhere from $3.6 \%$ to $5 \% .{ }^{54}$ The act may be particularly costly for small businesses. While the 2008 Act does not apply to employers that employ fewer than fifty employees, employers with fifty employees or more will need to make tough choices to comply with the act-either upgrade the mental health and substance abuse coverage they offer, or drop mental health benefits altogether. ${ }^{55}$ Steven Wojcik, vice president for public policy for the National Business Group on Health, has commented that the act will "definitely . . . make health-care costs more expensive [for smaller employers], so those employers operating at the margins may have a hard time continuing to offer [mental health] benefits." ${ }^{56}$ Additionally, increases in the cost of providing healthcare will trickle down from employers to their employees, adding another unwelcome burden for families in tough economic times. ${ }^{57}$

\section{Another Step Forward: Mental Health and Healthcare Reform}

After the Mental Health Parity Act of 2008, the push for parity took another step forward with the passage of healthcare reform in the form of the Patient Protection and Affordable Care Act, which was signed into law on

53. Tammy Worth, Cost Estimates Vary on Mental Health Parity Law, L.A. Times, Oct. 13, 2008, available at $\mathrm{http}: / /$ articles.latimes.com/2008/oct/13/health/hew-paritycost13.

54. Id.

55. Steve Twedt, Change in Federal Law Could Mean Small Companies Will Take a Big Hit on Insurance Rates, PittsBurgh Post-Gazette, Dec. 2, 2008, available at http://www.post-gazette.com/pg/ 08337/932022-28.stm.

56. Id.

57. See Worth, supra note 54. 
March 23, 2010. The healthcare reform law addresses many of the shortcomings of the 2008 Act, including one of the act's most glaring limitations - its application only to the private group health insurance plans of large employers. The healthcare reform law expands the parity mandate of the 2008 Act by requiring parity in all of the insurance plans offered in new state-run exchanges - new marketplaces where uninsured individuals and small businesses can purchase health insurance. ${ }^{58}$ This expansion should dramatically improve access to mental health care because it mandates the provision of mental health benefits in the market where 32 million currently uninsured Americans will be purchasing health insurance. ${ }^{59}$ The healthcare reform law's expansion of parity requirements is particularly important because advocates believe the mentally ill are "more likely to be uninsured than the general population." And, even if mentally ill people in the individual and small business markets do currently have insurance, their insurance plans are more likely to offer limited mental health benefits, if they include mental health benefits at all. However, the healthcare reform law's expanded parity requirements will not be realized until 2014, when the exchanges come online. ${ }^{61}$

The new healthcare reform law also addresses the 2008 Act's failure to require insurance plans to offer mental health benefits in the first place. While some states have laws mandating the inclusion of minimum mental health benefits in private insurance plans, the healthcare reform law goes even further by requiring that the insurance plans included in the state-run exchanges that the uninsured will buy into offer a minimum package of benefits, including benefits for mental health and addiction. ${ }^{62}$ While the exchanges will not be in place until 2014, the federally-mandated minimum mental health benefits are evidence of Congress' commitment to expanding access to mental health care.

However, while the new healthcare reform law addressed many of the shortcomings of the 2008 Act, other limitations of the 2008 Act remain unaddressed. One major limitation is that absent state law mandatory

58. Sarah Kershaw, Mental Health Experts Applaud Focus on Parity, N.Y. Times, Mar. 30, 2010, at D5.

59. See id.

60. Id.

61. See id

62. Judge David L. Bazelon Center for Mental Health Law, Senate Health Care Reform Bill: The Patient Protection and Affordable Care Act-Assessing the Impact for People with Mental Illness 5 (2009), available at http://www.bazelon.org/issues/healthreform/126AmendedSenateSummary.pdf. 
minimums in the level of mental health benefits offered by large employers, those employers can still legally drop mental health benefits. This is because both the 2008 Act and the new healthcare reform law still only require parity in the large employer market if the employer already offers mental health benefits - parity is not required when those benefits are simply not offered.

The limitation in federal parity and minimum benefits requirements is troubling for several reasons. First, the individual mandate in the new healthcare reform law requires people to purchase insurance, but those people who work for a large employer that offers insurance will, with limited exception, purchase insurance through their employer and not through the state-run exchanges. ${ }^{63}$ The healthcare reform law provides that for employers with fifty or more employees, the employer must provide a "free choice voucher" to employees with incomes less than $400 \%$ of the federal poverty level and whose share of the employer-sponsored insurance premium is between 8 and $9.8 \%$ of their income, so that those employers may purchase insurance through the exchanges rather than from their employer. ${ }^{64}$ However, employees who do not fall under that exception will have to purchase insurance through their employer-insurance that may not offer the mental health benefits they need. As a result, these employees may have to purchase separate insurance for their mental health care.

The limitation on federal parity and minimum mental health benefits is also problematic because the state laws that require the provision of minimum benefits do not apply to large employers that self-insure - that is, the practice by which employers pay employees' healthcare costs directly rather than purchasing insurance for them through an insurance company. Instead, such plans are exempt from state regulation under ERISA, the Employee Retirement Income Security Act. ${ }^{65}$ A 2002 study by the Kaiser Family Foundation/Health Research and Educational Trust found that about 52\% of workers with health insurance coverage are in a self-insured plan, and are therefore not covered by state parity laws. ${ }^{66}$

63. Keiser Family Found.: Focus on Health Reform, Summary of New Health Reform Law 1 (2010), available at $\mathrm{http} / / \mathrm{kff}$. org/healthreform/upload/8061.pdf.

64. Id.

65. Cong. Research Service, Mental Health Parity 16 (2003).

66. Id. 


\section{Looking Forward: Improving Access and Reducing Stigma Beyond Healthcare Reform and the 2008 Act}

While the kinks in the new healthcare reform law's parity provisions have yet to be worked out, several other provisions of the law will help begin the important work of further understanding mental illness, and improving the quality and efficacy of mental illness treatments. ${ }^{67}$ The law provides for research and funding to improve mental health care, including funding for emergency psychiatric treatment demonstration projects, national centers for excellence for depression, and research on quality gaps and patient-centered, effective treatments for mental health and substance abuse disorders. ${ }^{68}$ The healthcare reform law also improves access to mental health care by investing in the training, recruitment, and education of new mental healthcare professionals, and by encouraging collaborative, community-based care. ${ }^{69}$ These provisions represent a new milestone in Congress' recognition of the importance of quality and access in the treatment of mental illness in the U.S. As Michael Fitzpatrick, executive director of NAMI, noted on the passage of healthcare reform, the new law "can change the mental health system in America and ... give families and individuals an opportunity to get a level of access to care [they] could only fantasize about before." 70

Building on advances the research, training, and community care provisions of the healthcare reform law will yield, future parity legislation could go even further to improve access to mental health care by creating a new parity scheme - one that takes into account the fact that, while they are biological in nature, many mental health services do not have a direct physical healthcare counterpart, and are therefore unaffected by current parity laws. ${ }^{71}$ A new parity scheme might incorporate new understandings of mental illness, taking into account the differences between effective treatments in mental and physical healthcare to offer parity in the number, type, or dollar amount of effective treatments covered. In this way, future legislation can build on the groundwork first laid by Senator Wellstone and Senator Dominici in the 1996 Act to expand access to mental health care, and further reduce the stigma associated with mental illness.

67. $I d$.

68. Id. at $11,14 \& 16$.

69. Id. at 18-19.

70. Kershaw, supra note 59.

71. Supra note 66 , at 15. 